\title{
Explore Barriers that Prevent Student Nurses Practical Training
}

\author{
Rasha R.A.* Kamailia R.A.S. ** Amal A.H. *** Somaya O.A. *** \\ * Faculty of Nursing, Menoufiya University**Maternal \& Gynecological Nursing Department, Faculty of \\ Nursing ,Ain ShamsUniversity*** Women's Health \&Obstetrics Nursing, Faculty of Nursing Benha \\ University
}

\begin{abstract}
Aim: This study was to explore barriers that facing student nurses during their practical training at obstetrics and gynecological department. Setting: The study was conducted at the Obstetrical and Gynecological Department of the Faculty of Nursing at Benha University. Design: A descriptive design was utilized. Sampling: A convenient sample included (180) student nurses. Tools: Two tools were used, the first tool was interviewing questionnaire sheet for assessing the general characteristics of students and assessment of barriers which facing the student during their practical training. The second sheet was modified student satisfaction questionnaire. Results: Many barriers faced students during their practical training and $(72.2 \%)$ of students were unsatisfied while $(10.6 \%)$ of students were satisfied and (17.2\%) were satisfied to some extent and there was highly negative significant correlation between total barrier score and total satisfaction score ( $p>0.001)$. Conclusion: Many barriers faced the students during their practical training at the lab, the hospital and during the application of skills and nearly to third quarters of the total of students weren't satisfied with the practical training, there was highly negative significant correlation between total barrier score and total satisfaction score. Recommendation: Continuous evaluation of students' opinion regarding the teaching process, curriculum, their needs and satisfaction as a part of developmental plans of the quality of education.
\end{abstract}

Key words: barriers, practical training, student satisfaction

Introduction

Obstetrics is a branch of medicine pertains to the care of women during pregnancy. Gynecology is a branch of medicine that deals with the disease and treatment of the female reproductive system(Leifer, 2015).Nursing students become competent professionals through the clinical practice and the learning environment by preparing students to provide quality health care as well as promoting the health of different people (Henderson, 2011). All nursing education programs have a clinical component in which students are supervised by clinicians in the clinical setting. Education is provided to nursing students by experienced nurses and other medical professionals who have qualified for educational tasks. The practical learning environment helps student to become good nurse through exposure forcaring situation and demonstrating what is learnt in the theory (Adah, 2012\& Karen, 2013).

Barriers of the practical training are factors known to reduce the quality of the clinical placement experience.Barriers include occupational stress; psychological stressors such as high workload, problematic working relationship, lack of supervisors support and low level of recognition and reward are all too commonly reported in health service delivery environments. These 
induce states of anxiety, inhibit learning, and impair performance and compromise health and wellbeing (Australian Government Initiative, 2012).

Also, the results of many studies suggest that there is a relatively deep gap in trend of scientific nursing and midwifery training with clinical performance of students in such a way that the existing clinical trainings may not necessarily empower the student to acquire clinical competency and skill (Joekar\& Haghani, 2011).

Educators are facing different challenges in the clinical learning environment which are different from challenges encountered in the classroom because clinical setting require different approaches for teaching in a variety of settings (Ress\&Jolly, 2009).

\section{Significance of the study}

The more fruitful clinical training is presented, the more efficient nurses will be today students for tomorrow and a healthy community is the product of the efficient nurses (Sahebzamani et al., 2012). Practical education is acknowledged as an essential part of nursing education and there are some factors which may influence the quality of students learning in the practical training (Ghafourifard et al., 2016). The survey results indicated that between $49 \%$ and $53 \%$ of novice nurses were involved with errors in nursing care. So it is necessary to consider barriers facing students in the clinical training and maintain their satisfaction.

\section{Aim of the study}

Toexplore barriers that facing student nurses during their practical training at obstetrics and gynecological department.

\section{Research Questions}

- What are the barriers that facing student nurses during their practical training at obstetrics and gynecological department?

- Are student nurses satisfied with their practical training at obstetrics and gynecology department?

\section{Subjects and methods}

\section{Research design:}

A descriptive study design was utilized to achieve the aim of the study.

\section{Research Setting:}

The study was conducted at the Obstetrical and Gynecological Department (Women's Health \& Obstetrics Nursing Department) of the Faculty of Nursing at Benha University

\section{Sampling:} selected.

*Type: convenient sample was

*Sample size: All third year female nursing students. They were totaled (180 students) at the Obstetrical and Gynecological Department in the period from (2015-2016) during the second semester.

\section{Tools of Data collection:}

I-Interviewing questionnaire sheet

A -Structured questionnaire was constructed to assess student general characteristics such as (age, residence, qualification, attending summer training).

B- Assessed student nurses about barriers that facing them during their practical training. 


\section{Scoring system}

Scoring system for assessment of barriers of practical training

Each question was scored as (1) for correct answer and (2) for incorrect answer.

II- Modified student satisfaction questionnaire:

To assess student satisfaction about barriers that facing student nurses during their practical training at Obstetrical and Gynecological Department.

\section{Total satisfaction score was calculated as:-}

Unsatisfied-- $<60 \%$ of total knowledge score.

Satisfied to some extent ----------60-<75\% of total knowledge score.

Satisfied -------- $\geq 75 \%$ of total knowledge score.

\section{Ethical Considerations:}

-Consent was obtained from the Dean of Faculty of Nursing before conduction of the study

-The aim of the study was explained to the student before applying the tools to gain the student nurses' confidence and trust to participate in the study.

-Oral consent was obtained from each student nurse in order to participate in the study.

-Questionnaire did not include any harm and did not touch any religious and traditional issues among the study sample

- Freedom to withdraw from participation in the study at any time
-Maintain confidentiality, dignity and self-esteem of students.

-All tools of data collection were burnt after data analysis

\section{Operational Design:}

\section{Preparatory Phase:}

This phase started by reviewing the current and previous local and international related books, magazines, periodicals and computer search was done to get acquainted with the research study to develop the tools and contents.

\section{Pilot Study:}

A pilot study was carried out at February (2015-2016) on about $10 \%$ of the total students (18 student nurses). It was carried out to assess content validity of the used tool, ascertain the clarity and applicability of the study tools, and estimated time needed to fill the questionnaire.No modification was done and the pilot study was included in the sample

\section{Field work:}

This study was carried out from March(2016) until June(2016) duringthe academic year. The researchers attended at Faculty of nursing at Benha for two days(Monday and Thursday) per week from 9 a.m to 2 p.m according to student schedule to attend clinical lab at the faculty and also hospital practical training.

The researchers introduced themselves and explained the purpose of the study to each student nurses to obtain student nurse consent to accept to participate in the study and to gain their confidence and trust then the researchers interviewed each student individually 15 minutes and the time of collecting all data took 3 months 
Then the researcher administered the interviewing questionnaire tool and assessment of barriers which facing student nurses during their practical training firstly then the modified student satisfaction tool was administrated to student nurse to assess their satisfaction regarding their practical training.

The researcher clarified any question to the study sample if needed and interviewed 6 students /day.This was repeated until the sample size was completed.

\section{Limitations of the study:}

Space time of participating students was limited and the researcher make more effort and needed more time to collect the data from the students.

Results: $(\mathbf{n}=\mathbf{1 8 0})$

Table (1): Distribution of studied students according to their general characteristics

\begin{tabular}{|l|c|c|}
\hline General characteristics & No. & $\%$ \\
\hline Age by years & 5 & 2.8 \\
\hline $19-<20$ & 63 & 35 \\
\hline $20-<21$ & 78 & 43.3 \\
\hline $21-<22$ & 34 & 18.9 \\
\hline $22-<23$ & \multicolumn{3}{|c|}{$20.8 \pm .814$} \\
\hline Mean \pm SD & 132 & 73.3 \\
\hline Place of residence & 48 & 26.7 \\
\hline Rural & \multicolumn{3}{|c|}{} \\
\hline Urban & & \\
\hline Qualifications & 145 & 80.6 \\
\hline Secondary School & 35 & 19.4 \\
\hline Nursing Institute & & \\
\hline Attending summer training & 62 & 34.4 \\
\hline Attended & 118 & 65.6 \\
\hline Not Attended & & \\
\hline
\end{tabular}

Table (1) shows the general characteristics of the study sample. Regarding age, $\mathbf{3 5 \%}$ and 43.3\% of students were between 20 and 21 of age respectively with mean \pm SD of $20.8 \pm .814$, while $\mathbf{7 3 . 3 \%}$ of the students lived in rural areas and $\mathbf{8 0 . 6 \%}$ of them at the secondary school before joining the university and $\mathbf{6 5 . 6 \%}$ of them did not attend practical training or work in the hospitals during the summer holiday. 
Rasha R. A., Kamailia R. A., Amal A., \& Somaya O. A.

Table (2): Frequency distribution according to self-reported barriers among the studied sample at the Faculty Lab $(n=180)$

\begin{tabular}{|l|l|l|l|l|}
\hline Barriers at the faculty lab & Yes & No \\
\cline { 3 - 5 } & No. & \% & No. & \% \\
\hline Lab equipment are conformity with needed student skills & 65 & 36.1 & 115 & 63.9 \\
\hline Presence of identity card on every equipment at the lab & 69 & 38.3 & 111 & 61.7 \\
\hline Existing equipment at the lab are correctly working & 49 & 27.2 & 131 & 72.8 \\
\hline There is chance to every student to deal with devices & 37 & 20.6 & 143 & 79.4 \\
\hline A sign boards for each device at the lab & 71 & 39.4 & 109 & 60.6 \\
\hline Smoking prevention advertisements at the lab & 114 & 63.3 & 66 & 36.7 \\
\hline An obligation of entrance time and required uniform & 117 & 65.0 & 63 & 35.0 \\
\hline Cooperation of technicians working at the lab & 72 & 40.0 & 108 & 60.0 \\
\hline Back door at the lab to get out if there are any problem & 45 & 25.0 & 135 & 75.0 \\
\hline Availability of alarm fire and extinguisher device at the lab & 127 & 70.6 & 53 & 29.4 \\
\hline Lab is orderly and clean & 124 & 68.9 & 56 & 31.1 \\
\hline Lab is good lighting and the ventilation & 108 & 60.0 & 72 & 40.0 \\
\hline An area of the lab is enough for the number of students & 46 & 25.6 & 134 & 74.4 \\
\hline
\end{tabular}

Table(2)shows $79.4 \%$ of students find that lack of chance to every student to deal with the devices was the most barrier.75\% of the student find there was no back doorat the lab to get out if there were any problem $.74 .4 \%$ find that the lab space was not enough and not suitable for the number of students was another barrier but $72.8 \%$ of students find that the equipment at the lab weren't correctly working was other barrier $.63 .9 \%$ of students said that lab equipment weren't conformity with the needed student skills. 
Table (3): Frequency distribution of studied sample according to their self-reported barriers at the hospital $(n=180)$

\begin{tabular}{|c|c|c|c|c|}
\hline \multirow{2}{*}{ Barriers at the hospital } & \multicolumn{2}{|l|}{ Yes } & \multicolumn{2}{|l|}{ No } \\
\hline & No. & $\%$ & No. & $\%$ \\
\hline Health team welcome attending student & 88 & 48.9 & 92 & 51.1 \\
\hline The health team applied the ethics of the nursing profession & 75 & 41.7 & 105 & 58.3 \\
\hline Availability of the written instructions for the department & 91 & 50.6 & 89 & 49.4 \\
\hline Fire extinguishers and fire safety Appliance are available & 97 & 53.9 & 83 & 46.1 \\
\hline Preventing the smoking at hospital departments & 47 & 26.1 & 133 & 73.9 \\
\hline Availability of personal protective equipment & 71 & 39.4 & 109 & 60.6 \\
\hline $\begin{array}{l}\text { There is a place in the hospital to maintain the student } \\
\text { privacy }\end{array}$ & 106 & 58.9 & 74 & 41.1 \\
\hline Training place is far from the place of residence & 94 & 52.2 & 86 & 47.8 \\
\hline There is a place for health education and counseling & 75 & 41.7 & 105 & 58.3 \\
\hline $\begin{array}{l}\text { There is accurate system for recording and reporting needle } \\
\text { steel injuries }\end{array}$ & 133 & 73.9 & 47 & 26.1 \\
\hline Sometimes there are no cases for training in hospital & 71 & 39.4 & 109 & 60.6 \\
\hline I was satisfied in hospital training more than lab training & 110 & 61.1 & 70 & 38.9 \\
\hline $\begin{array}{l}\text { Availability of decontamination basin for equipment } \\
\text { processing }\end{array}$ & 105 & 58.3 & 75 & 41.7 \\
\hline Availability of decontamination solution for used tool & 96 & 53.3 & 84 & 46.7 \\
\hline $\begin{array}{l}\text { Changing the sheets which cover the bed when become } \\
\text { soiled }\end{array}$ & 112 & 62.2 & 68 & 37.8 \\
\hline There is a correct system for garbage disposal & 53 & 29.4 & 127 & 70.6 \\
\hline Nurses provide competent nursing care & 116 & 64.4 & 64 & 35.6 \\
\hline $\begin{array}{l}\text { Students agree for periodic examination and check up to } \\
\text { avoid viral infection }\end{array}$ & 125 & 69.4 & 55 & 30.6 \\
\hline $\begin{array}{l}\text { There is a box for syringe to be kept and avoid recapping the } \\
\text { needle }\end{array}$ & 116 & 64.4 & 64 & 35.6 \\
\hline
\end{tabular}

Table(3)shows third quarter(>70\%) of the sample find the most barriers are the following(no prevention of the smoking at the hospital departments and there was no correct system for garbage disposal) while $\mathbf{> 6 0 \%}$ find these barriers (personal protective equipment aren't available at the 
department) but $\mathbf{> 5 0 \%}$ find these barriers (Health team did not welcome attending student, the health team did not apply the ethics of the nursing profession, there was no place for health education and counseling, training place was far from the place of residence).

Figure (1): Percentage of total satisfaction scoring of student regarding their practical training at different aspects (lab, hospital and curriculum

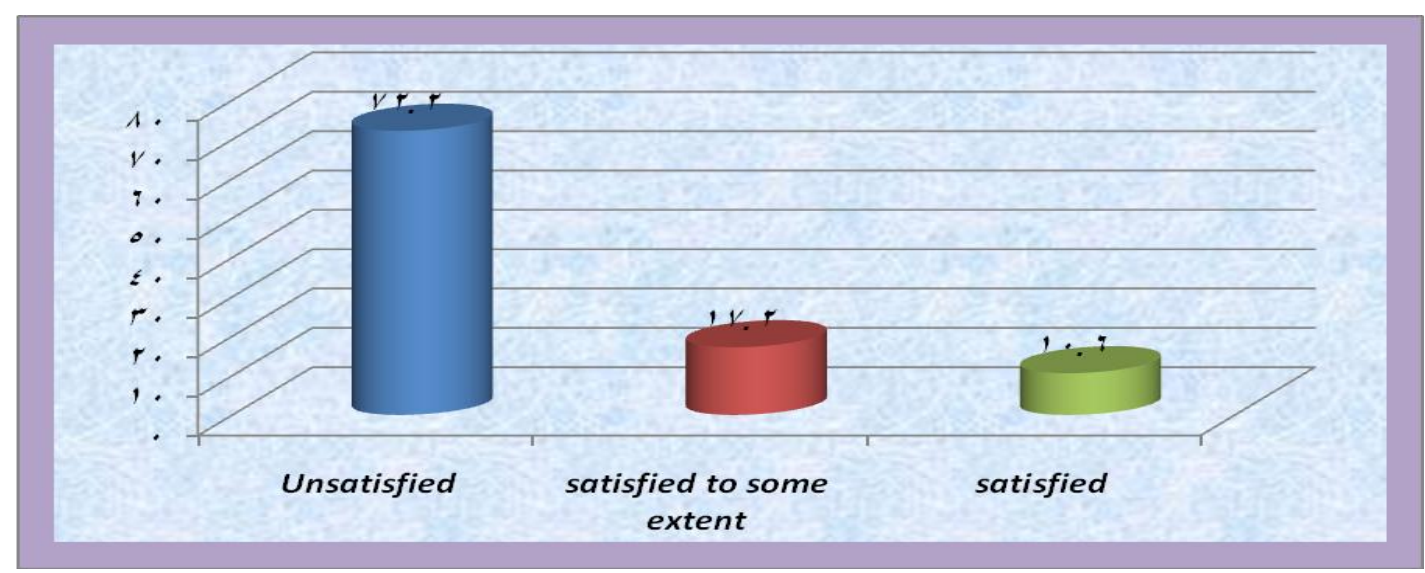

Figure (1) shows $72.2 \%$ of students were unsatisfied with their practical training. $17.2 \%$ of the students were satisfied to some extent with their practical training.10.6 of the students were satisfied with their practical training.

Table (4): Correlation between total barriers and total satisfaction score.

\begin{tabular}{|c|c|c|}
\hline \multirow{2}{*}{ Total } & \multicolumn{2}{|c|}{ Total barriers } \\
\cline { 2 - 3 } & $\mathbf{R}$ & p-value \\
\hline Total Satisfaction & $\mathbf{- 0 . 3 5 6}$ & $\mathbf{0 . 0 0 0} * *$ \\
\hline
\end{tabular}

$* *$ High statistical significant at p-value $<0.001$

Table (4) shows that there was a highly negative significant correlation between total barriers score and total satisfaction score.

Discussion:

Regarding to student self-reported barriers during their practical training at the lab, the result of the present study revealed that, nearly of three quarters of the student nurses reported that, lack of chance to every student to deal with the devices was the most common barrier at the lab. According to AbdEl-Mordy (2015)in the study of Assessment of Practical Skills regarding Emergency situation in the Delivery Unit indicated that, the most of students in all studied departments had little period for training while more procedure needed more time so students needed more time for training. Contrary, Erlich (2009) found in the study about the advantage of modern laboratory skills that the modern laboratory skills provide grate environment of updated practice for students and give students an opportunity to repeat the procedures many times. These different findings may be due to increase the number of students in the 
learning group and there is lack of available numbers of dolls because its high cost.

The result of the present study revealed that the lab space was not enough and not suitable for the large number of students was another barrier. A study conducted by Dessie (2007)in the study of An Investigation of Clinical Assessment Processes of Student Nursesrevealed that, the lab and class size play an important role in student clinical achievement; more over the stress point of the study creating healthy class or lab as a healthy environment for clinical achievement.

The result of the present study illustrated that, certain devices at the lab weren't correctly working which was another barrier. The findings of the current study was in disagreement with Saker (2011) reported in a study about effects of educational program on performance of nursing care, the laboratory equipped with all modern facilities, infrastructure for providing best education environment and the students gained the real-world experience in supervising the clinical placement in affiliated local health care and perhaps the reason of this difference is the difference in the research environments in both studies. Likewise these different results may be related to reduce the faculty budget which is allocated for increasing the modern equipment and supplies at the labs.

Additionally the present study revealed that there was no back door at the lab to get out during emergency situation to ensure safety. The result of the present study was in disagreement with Jones, (2010) who indicated that, in a study about the best training environment, the laboratory provided a safe environment for nursing students to practice the clinical performance skills.

Concerning student self-reported barriers during their practical training at the hospital, the results of the present study revealed that, the student nurses reported that health team at the hospital didn't welcome the presence of the student. On the other hand the results which were documented by Hanifi et al. (2012)in the study of The miracle of communication as a global issue in clinical learning motivation of nursing students reported that proper communication with students increased the motivation.

These findings were matched with the results of the study which conducted by Jamshidi et al. (2016)in the study of The Challenges of Nursing Students in the Clinical Learning Environment who demonstrated that, conflicts and improper treatment between the staff and students negatively affect the practical teaching. Furthermore, the results of the present study revealed that the majority of the student nurses reported that personal protective equipments were not available at the department. These findings were similarity to Flott \& Linden, (2015) who reported that other barrier to clinical education was related to un-standardized wards with inadequate facilities and not providing an opportunity for doing nursing care independently. It was obvious that clinical learning needed some facilities and equipment in clinical settings which develop the clinical experiences of nursing students. Unfortunately most of our hospitals are old and have not been appropriately designed for clinical training. Therefore when the ward is overcrowded, clinical teaching is influenced and becomes difficult to perform an effective teaching and for solving these problems, collaboration between healthcare agencies and nursing education have been proposed for conducting an effective clinical learning.

According to satisfaction of students, regarding practical training curriculum .The result of the current study revealed that some of students were satisfied with the presence of inter linkages between the theoretical and the practical training evidence. The present study was in the same line with the study conducted by Chen, (2012) in the study of Development and 
psychometric testing of the nursing student satisfaction scale for the associate nursing programs reported that curriculum issues were also perceived by nursing students as important such assimilarity of the content with the practice reality, and curricular capability to promote training that was consistent with market demand. Distribution of curricular content, consistency of the offered disciplines.

\section{Concerning the correlation between} total barriers and total satisfaction score, the current study revealed that there was a highly negative significant correlation between total barriers score and total satisfaction score. While, the study of Edraki (2011) in the study of The Relationship between Nursing Students' educational Satisfaction and their academic success reported that there was a positive correlation between the rate of satisfaction about the field of study and academic achievement in students .This may be due to different in culture facilities and educational levels.

\section{Conclusion:}

There were many barriers faced student nurses during their practical training at the faculty lab, hospital and during the application of the practical skills. The nearly of three quarters of studied sample weren't satisfied with the role of the teacher either at the hospital or the lab and also with the practical training curriculum. There was a highly negative significant correlation between total barriers score and total satisfaction score.The above-mentioned findings have mainly answered the study questions.

\section{Recommendations:}

-Dividing students into small groups to provide chance for each student to deal with the devices and apply training procedures and maintaining appropriate learning environment
-Collaboration between the hospital and the faculty for providing protective personal equipment for students and respect their role.

\section{References:}

Abd El-mordy, Z, El-kholy,G, Abd-El salam, S (2015): Assessment of Nurses Practical Skills regarding Emergency situations in the Delivery unit, Literature review, p71

Adah, C. (2012): Clinical performance of nursing students. Retrievedfrom:http://www.ehow.Com/ab out-6163234clinical-performancenursing student. htmp.

Australian Government Initiative (2012): Promoting quality in clinical placement. Retrievedfrom:www.Hva.Gov/An/Sites/U ploads/Promotin.g-Quality-In-ClinicalPlacements-Report-20130408.Pdf.

Chen, H. (2012): Development and psychometric testing of the nursing student satisfaction scale for the associate nursing programs. J Nurs Educ Pract.; 2(3):25-37.

-Dessie, W. (2007): An Investigation of Clinical Assessment Processes of Student Nurses in Jakarta, Indonesia 2007. Australian Catholic University Locked Bag 4115, Fitzroy, and Victoria 3065 Australia

Edraki M, Rambod M, Abdoli R. (2011): The Relationship between Nursing Students' educational Satisfaction and their academic success. Iranian journal of medical education. 11(1):32-39. Persian.

Erlich, W., A. (2009): Hand book of advantage of modern laboratory skills, $3^{\text {rd }}$ ed, Jones and Bartlett publishers, pp 356,358 . 
Flott, E. A., \&Linden, L. (2015): The clinical learning environment in nursing education: A concept analysis. Journal of advanced nursing.

Ghafourifard, M., Bayandor, A., \& Zirak, M. (2016): Clinical education status in educational centers affiliated to Zanjan University of medical sciences from nursing and midwifery students' viewpoint. Journal of Medical Education Development, 8.(20)

Hanifi, S. Parvizy, \& Joolaee, (2012): The miracle of communication as a global issue in clinical learning motivation of nursing students, Procedia-Social and Behavioral Sciences, vol. 47, pp. 1775Available online at www.sciencedirect.com.

Henderson, A. (2011): Leadership in clinical education: embedding learning in everyday practice. Nurse Education Today; 31: 4-5.

Jamshidi, N, et al., (2016): The Challenges of Nursing Students in the Clinical Learning Environment: A Qualitative Study, Volume 2016 , Article ID 1846178, 7 pageshttp ://dx.doi $\quad$.org/10 $.1155 / 2016$ $/ 1846178$.

Joekar F, Haghani F. (2011):.Nursing clinical Education the challenges Facing. Iranian
Journal of Medical (education; 10(5):1153-1160 (Persian)

Jones, M. (2010): Improving the job training, $2^{\text {nd }}$ ed San Francisco: Jossey-Bass, pp5564.

Karen, M. (2013): Clinical Nursing Education: current reflection. Portland. Retrieved from: www.thefreelibrary .com/clinical+Nursing +Eduction\% 3a+ current+ Relection-0234930406.

Leifer, G. (2015): Introduction to maternity and pediatric nursing, Chapter 1. 7th ed., p5.

Ress, L., A, \& Jolly, A., H. (2009): The purpose of clinical training, 4th ed., NewYork, John Wiley and sons, p259.

Sahebalzamani M, Salahshurianfard A, Akbarzadeh,etal., (2012): Comparison of barriers and facilitators of effective clinical training Views of nursing Teachers and students in Islamic Azad university of Maragheh. Journal of Islamic Azad University of medical school; 21(1): 38-43.

Saker, F. (2011): Effect of an educational program on performance of nursing care for post-operative kidney transplantation patient, Doctorate thesis. Faculty of Cairo, Cairo University, p140. 